The Short and Long-term I mact of I nt er nat i onal Mgr at i on on Human Capi tal For rat $i$ on of the Lef $t$ Behi nd

\begin{tabular}{|l|l|}
\hline 著者 (英) & Pr anød Kumar Sur \\
\hline $\begin{array}{l}\text { j our nal or } \\
\text { publ i cat i on ti t l e }\end{array}$ & AGl Wbrki ng Paper Seri es \\
\hline vol une & $2020-02$ \\
\hline page range & $1-24$ \\
\hline year & $2020-01$ \\
\hline URL & ht t p: //i d. ni i .ac.j p/1270/00000166/ \\
\hline
\end{tabular}




\title{
The Short and Long-term Impact of International Migration on Human Capital Formation of the Left Behind
}

\author{
Pramod Kumar Sur \\ Asian Growth Research Institute (AGI) and Osaka University \\ Working Paper Series Vol. 2020-02
}

January 2020

The views expressed in this publication are those of the author(s) and do not necessarily reflect those of the Institute.

No part of this article may be used reproduced in any manner whatsoever without written permission except in the case of brief quotations embodied in articles and reviews. For information, please write to the Institute. 


\title{
The Short and Long-term Impact of International Migration on Human Capital Formation of the Left Behind
}

\author{
Pramod Kumar Sur \\ Asian Growth Research Institute (AGI) and Osaka University
}

\begin{abstract}
This paper examines the short and long-term impact of international migration on overall human capital formation as well as the quality of human capital formation of the left behind households in the community of origin. Exploiting a unique migration policy, we find that the time passed since the migration event took place could affect the human capital formation of the left behind households differently. Furthermore, we find that international migration could also impact overall human capital as well as the quality of human capital formation differently. In particular, we do not find any impact of short and long-term international migration on the overall human capital formation of the left-behind household members. However, we find that households with long-term migrants are more likely to switch from a lower quality of education and substituting it with a higher quality of education of the left behind household members.
\end{abstract}

Keywords: International Migration, Human Capital Formation, Education JEL Code: F22, J24, I21 


\section{Introduction}

It is well accepted that the international migration can have both positive and negative impact on the human capital formation of the left behind. However, it is not well known whether the time passed since the migration event took place (years of migration in general) may affect the outcomes as the researcher does not always observe it (Antman 2013). Furthermore, relatively less is known whether it also affects the quality of human capital formation of the left behind.

In this paper, we examine the short and long-term impact of international migration on overall human capital formation as well as the quality of human capital formation of the left behind households in the community of origin. In order to provide rigorous evidence, we address the two most important challenges that are well known in the field of migration studies. Foremost, high-quality and household level data on migration is generally not available, especially in developing countries. Therefore, it is difficult to examine the impact of migration on various outcomes in detail. Furthermore, there is a selection problem in most migration studies. Gibson et al. (2013) call it the quadruple selectivity problem. First, households selfselect into migration. Second, migrant households choose whether everyone will migrate or send some of their members. Third, some migrants decide to return however others decide not to return. And fourth, migrants choose when to return. Therefore, comparing migrant households with general population might provide biased results as a host of observable and unobservable differences exist between people who choose to migrate and those who stay behind. A better comparison is possible if the control and treatment groups have equivalent characteristics or similar in most or all dimensions. In other words, migration of an individual or household is random or by chance.

We conducted a customised survey and examine the short and long-term effect of labour migration from Nepal to South Korea under Employment Permit System (EPS). The institutional setup of EPS allows us to mitigate challenges mentioned above. First and foremost, under EPS program, workers are randomly selected and introduced to employers for employment in South Korea after passing a Korean language test. Therefore, although workers will eventually migrate, the specific timing of migration to work in South Korea is quite randomly decided. Additionally, this program does not allow other household members to migrate together. Furthermore, the contract period to work in South Korea is largely fixed. And finally, workers have to return back to their home country after the completion of their contract. 
Therefore, our setting could be ideal to examine the causal effect of international migration on human capital formation in the country of origin.

Nepal offers several unique advantages to examine our research question. In the past, international migration was not a general phenomenon in Nepal except going to India. ${ }^{1}$ However, there has been a sudden surge to work abroad in recent years. For example, only 3605 and 27796 labour permits to work abroad were issued in 1993-94 and 1999-00 respectively, however, the number of permits has increased to 499620 in 2014-15. Similarly, the inflow of remittances has surged more than ten folds in 11 years from 58.6 billion in 200304 to 589.5 billion (in Nepalese Rupees) in 2014-15. The remittances contributed 27.7 percent of Nepal's GDP in 2014-15, the third largest recipient of remittance in the world as a share of GDP and the top recipient among least developed countries. ${ }^{2}$ Therefore, it would be motivating to examine whether international migration from Nepal contributes to the overall human capital formation as well as the quality of human capital formation. Although there are various programs under which Nepalese workers work abroad, we concentrate our analysis to EPS program to provide a causal evidence of international migration on human capital formation of the left behind household members.

Our focus on the impact of both short and long-term migration is important. Previous research suggests that migration could have a positive effect on the human capital formation through relaxing credit constrain (Cox-Edwards and Ureta 2003, Hanson and Woodruff 2003, Yang 2008, Ambler et al. 2015, Dinkelman and Marioti 2016), changes in household decision making power (Clemens and Tiongson 2017) and brain gain (information regarding the value of education) resulting from migration (Batista et al. 2013, Acharya and Gongalez 2014). On the contrary, migration could have a negative impact on the human capital formation by parental absence from home, (Booth 1995, Giannelli and Mangiavacchi 2010; Antman 2012) children's migration and increased housework (McKenzie and Rapoport 2011). ${ }^{3}$ However, the positive and negative impact may differ based on time elapsed since the migration event took place. For example, there is a higher possibility that the household credit constrains will persist even after the migration especially in the beginning period and may phase out in the long run.

\footnotetext{
${ }^{1}$ Nepalese citizens do not need a work permit to work in India. Nepalese citizens are free to move and work in India without even a passport.

${ }^{2}$ Ministry of Labour and Employment, Government of Nepal, Labour Migration for Employment A Status Report for Nepal: $2014 / 2015$,

${ }^{3}$ Although there are many researches done in this field, we restrict the literature that tries to provide a robust identification strategy to provide a causal impact. For a detail literature review in this field, please refer to Antman (2013).
} 
Similarly, brain gain is more likely to be positively correlated with migration experience.

Our focus on both overall as well as the quality of human capital formation is essential as well. Overall human capital formation may rise over time but the quality of human capital may decline. For example, according to ASER survey (by Pratham in India), the overall enrolment is consistently increasing in India. ${ }^{4}$ However, the quality of education measured is declining. According to the report around $59 \%$ of $4^{\text {th }}$ graders and $44 \%$ of $5^{\text {th }}$ graders in India can only read below $2^{\text {nd }}$ grade level texts. Similarly, $76 \%$ of $4^{\text {th }}$ graders and $63 \%$ of $5^{\text {th }}$ graders cannot do even a simple division. Similar patterns have also been found in other developing countries such as Pakistan (Andrabi et al. 2007), Kenya (Duflo et al. 2011). Motivated by the findings, we focus our attention on whether international migration has any effect on both overall as well as the quality of human capital formation of the left behind.

We briefly summarize the main findings below. We find a significant positive impact of long-term international migration on the quality of human capital formation. We find that long-term migrant households are 16-17 percentage points more likely to shift from a lower quality of education and substituting it with a higher quality of education of the left behind household members. However, we overall do not find any impact of short and long-term international migration on the overall human capital formation (in terms of education) of the left-behind household members. Similarly, we do not find any association between short-term international migration and the quality of human capital formation of the left behind household members. We provide various potential mechanisms behind our findings.

Most research on international migration literature that tries to capture the timing of migration generally focused either on short-term or long-term effect. This paper contributes to the literature by examining both short-term as well long-term impact of international migration on human capital formation. Our findings suggest that the time elapsed since the migration event took place could affect the human capital formation of the left behind households differently. Similarly, international migration could also impact overall human capital as well as the quality of human capital formation differently.

Our study also provides a methodological contribution to the literature that studies the causal impact of international migration through a randomized process such as Gibson et al.

${ }^{4}$ ASER 2014: annual status of education report. 
(2011) and Mergo (2016). It is well known that migration is always self-selected. A further complication is that, among the migrants, households choose whether everyone will migrate or send some of their members. In such cases, it would be difficult to examine the causal effect of migration properly. One advantages of the EPS program is that it does not allow other household members to migrate together. Therefore, we overcome the drawback of randomized policy limitations studied previously.

The rest of the paper is organized as follows. Section II discusses the Education system in Nepal. Section III presents a preliminary introduction to the EPS policy in Nepal. Section IV describe the dataset and examines the test of randomization. Section V analyzes the main results. Section VI presents the robustness to our main findings. Section VII describes the potential Mechanism behind our findings and finally, section VIII concludes.

\section{Education in Nepal}

The education system in Nepal has evolved over time. ${ }^{5}$ At present, the Interim Constitution of Nepal considers the first eight years of basic education as human rights. ${ }^{6}$ Education up to secondary level is provided for free in public (community) schools in the native language. The net school enrolment rate is quite high for the first five year of primary education $(96.2 \%$ in 2015) but suddenly decline with the next three years of lower secondary and at the secondary level (74.6\% and 56.1\% in 2015 respectively). ${ }^{7}$ Furthermore, despite significant improvement in net enrolment rates in primary/basic education, the National Review Report (2015) prepared by the Ministry of Education and the UNESCO state that, it has been a massive challenge to improve the internal efficiency of school education to ensure quality education to all eligible children of Nepal.

There is a significant difference in the quality of education between public and private schools in Nepal. Public schools in Nepal are commonly characterized by poor infrastructure facilities, low quality of teachers, weak management and regulation, and lower level of student achievement. On the other hand, private schools are for-profit institutions that aim for higher levels of academic achievement in preparing for national examinations (Thapa 2015). Due to the poor quality of community schools, private schools are preferred and provide a higher quality education on average in Nepal.

\footnotetext{
${ }^{5}$ Acharya and Gongalez (2014) and Thapa (2015) provide an excellent overview of the history and current education status in Nepal.

${ }^{6}$ Education for all national review report 2001-2015, Published in 2015 by the United Nations Educational, Scientific and Cultural Organization Office in Kathmandu.

${ }^{7} \mathrm{http}: / / w w w . m o e . g o v . n p / a s s e t s /$ uploads/files/Nepal_Education_in_Figures_2015.pdf
} 
There is a general demand for English as the medium of education from parents and communities in Nepal. ${ }^{8}$ In addition to be one of the highest migrants sending countries, Nepal also sends many students to study abroad. For example, by country of origin, Nepal ranks 13 among the number of international students studying in the US in $2016 / 17 .{ }^{9}$ The number of students studying abroad has shot up from a barely 3840 in 1998 to 30186 in $2013 .{ }^{10}$ Therefore, English medium education is very popular in Nepal. To meet the demand, most private schools offer the education in English medium. Anecdotal evidence also suggests that the public schools have also started providing education in English medium to attract good students. ${ }^{11}$ For these reasons, English medium education in general is popular and the quality is higher than Nepali medium education on average.

\section{Introduction to EPS Policy in Nepal}

The Employment Permit System (EPS) is a government-to-government agreement that allows foreign workers to work in South Korea. This program only allows workers to work temporarily in South Korea. Foreign workers under this program work in small enterprises (fewer than 300 employees) and perform mostly low-skilled jobs. In order to protect the employment opportunity of native workers, employers in South Korea can only apply for Employment Permit at Job Centers in case of having failed to employ native workers in spite of the efforts to hire them (for 3 to 7 days). The EPS program presently recruits workers from 16 different developing countries in Asia. ${ }^{12}$

The EPS program in Nepal started with the signing of MOU between the Government of Nepal and South Korea in 2007. Individuals between the age of 18 and 39 with no criminal records are eligible to apply for this program. Government institutions or agencies both in Nepal as well as in South Korea conduct all the recruiting processes. Therefore, there is no room for charging higher amount of fees over and above the required amount, which is general in the case of recruiting workers to work abroad especially in developing countries like Nepal. Anecdotal evidence as well as various newspaper reports also supports the evidence that there is less corruption involved in EPS selection process. Therefore, the EPS program is competitive

\footnotetext{
${ }^{8}$ School Sector Development Plan 2016/17-2022/23, Ministry of Education, Nepal http://www.moe.gov.np/assets/uploads/files/SSDP_Book_English_Final_July_5,_2017.pdf

9 https://www.statista.com/statistics/233880/international-students-in-the-us-by-country-of-origin// accessed 22 February 2018

${ }^{10} \mathrm{http} / / /$ data.un.org/Data.aspx?d=UNESCO\&f=series\%3AED_FSOABS

${ }^{11} \mathrm{http}$ ://bostonreview.net/education-opportunity/nepal-english-language-education. Accessed 19th June 2018

$12 \mathrm{https} / / /$ www.migrationpolicy.org/article/south-korea-carefully-tests-waters-immigration-focus-temporary-workers
} 
and very popular among Nepalese because of the government-to-government initiative that enables higher wage, better living and working conditions, with low corruption involved.

The recruiting process for EPS workers is quite long. In Figure 1, we present the qualification, implementation, and the employment procedure for the EPS program as referenced from the EPS website. In Figure 2, we present the general selection process. First, eligible applicants apply for the program at the EPS Korea Section in Nepal. Then each applicant has to appear and pass a Korean Language Test (Paper Based Test or PBT) to be eligible to work in South Korea. ${ }^{13}$ After passing the test, applicants fill out a job application form at the EPS Korea Section office in Nepal. Then, applicants are randomly drawn and introduced to the employers in South Korea for employment within two years from the date of the announcement of test results. ${ }^{14}$ After being selected, applicants go through one week of basic Korean language and culture training in Nepal and fly to South Korea for work mostly within one month.

According to the EPS, applicants are randomly drawn and introduced to the employer for employment in South Korea in order to maintain the transparency of the foreign workforce selection and introduction process. Therefore, an applicant's timing of going to South Korea depends upon the random draw and employer's selection, which continues for two years. For example, if a person has passed the Korean language test on $1^{\text {st }}$ December 2010, she/he is eligible to migrate to South Korea from $1^{\text {st }}$ December 2010 until $30^{\text {th }}$ November 2012. Furthermore, the Korean language test to be eligible to work in South Korea is conducted almost every year. ${ }^{15}$ As the process of introducing applicants goes on for two years, applicants from two different tests taking years are selected simultaneously. Therefore, applicants are treated in a similar manner after winning the lottery even if they have appeared the language test and were selected in different years. For example, the workers from 2010 and 2011 test cohorts will be treated similarly after the 2011 test result is declared. These policies act as our identification strategy to (plausibly) eliminate the selection biases and provide causal evidence.

The EPS program only allows workers to work temporarily in South Korea. The usual EPS contract period is for three years and employers can extend a worker's contract period to a maximum up to four years and ten months. Workers have to return back home after the expiry

\footnotetext{
${ }^{13}$ The minimum score to pass the examination is 80 out of 200 . However, due to a limited number of quotas every year, a designated number of candidates pass in order of their highest score on the test. The test score is valid for two years from the date of announcement of the result.

${ }^{14}$ https://www.eps.go.kr/ph/index.html?natNm=ph (Last, accessed 11 Jan 2019)

152009 test was abandoned possibly due to the financial crisis. 2012 test was not conducted as the South Korean government selected around 15678 workers in 2011 which was more than three times of workers selected in 2010 . There was no information beforehand that the 2009 and 2012 tests are going to be abandoned.
} 
of their contract period and can go back again with a new contract. ${ }^{16}$ As the average wage in the South Korea is extremely high in comparison to Nepal (almost 8 to 10 times on average), most workers return and opt to go back again with a new contract. Conversation with the workers during our survey also suggests that most workers are willing to go back to South Korea again with a new contract as long as they meet the eligibility criteria (especially age).

We analyse three kinds of households based on their migration experience: households with no migration experience, households with short-term migration experience and households with long-term migration experience. We term 'households with no migration experience' to those with a member who have passed the Korean language test (PBT), won the EPS lottery and were in the process of going to South Korea to work for the first time (blue part in Figure 2) at the time of the field survey. ${ }^{17}$ We consider this group as our control group households with no migration experience. We term 'households with short-term migration experience' to those with a member who is presently working in South Korea under his/her first contract (grey part in Figure 2). We consider this group as our first treatment households with short-term migration experience. We term 'households with long-term migration experience' to those with a member who has already completed his first contract period. These migrant households include those who have returned from South Korea, waiting to go back again or has already gone back again with a new contract (red part in Figure 2). We consider this group as our second treatment households with long-term migration experience.

\section{Description of the Dataset and the Test of Randomisation}

In this paper, we combine and use three different datasets. First, we conducted a customized field survey between September and October 2015 to collect information about these households. ${ }^{18}$ Second, the information regarding the number of schools in each district in Nepal is sourced from the data collected by Institute of Engineering, Pulchwk Campus in Nepal. ${ }^{19}$ And finally, the population of a district in Nepal is sourced from the 2011 census. ${ }^{20}$

\footnotetext{
${ }^{16}$ Foreign workers who have worked for four years and ten months without changing their workplace are considered as 'committed workers'. Workers with these characteristics can come back to the South Korea with a new contract after three months of departure and work for an additional four years and ten months in the same organization. Workers who have worked three years or more under the EPS system but without the characteristics mentioned above, that belong to the age group between 18 and 39 years, and have no illegal records are eligible to go to the South Korea through a special Korean language test (Computer-Based Test or CBT).

${ }^{17}$ We did not include those who have not won their employment lottery in our control group, as we do not know whether they will definitely go under this program or not.

${ }^{18}$ Detail information about the data collection process in the field can be found in Sur and Sasaki (2019)

$19 \mathrm{http} / / /$ data.opennepal.net/content/number-school-nepal-year-2007-2011

${ }^{20} \mathrm{http}: / /$ dataforall.org/dashboard/nepalcensus/
} 
We present the descriptive statistics and the test of randomization to our sample dataset in Table 1. In column 1 and 2, we show the descriptive statistics of our control group households. Furthermore, we present the descriptive statistics of households with short-term migration experience (the first treatment group) in column 3 and 4. In column 5 and 6, we present the descriptive statistics of households with long-term migration experience (the second treatment group). And finally, in column 7 and 8, we present the difference between control and treatment group households and their statistical significance on average to test the randomization of our sample datasets.

The first three variables shown in Table 1 are the outcome variables. We consider the current educational attainment of left behind household members as a measure of the overall human capital formation. The question asks whether any household member(s) is currently attending any kind of education or not. There are various measures to examine the quality of human capital formation such as quality of schooling (public v's private), test scores, grade progression and so on. In the context of Nepal, public and private institutions provide education in different languages. Therefore, it would be difficult for us to compare the test scores and grade progression as a measure of quality of education. Considering the education system in Nepal, recent trends and anecdotal evidences as discussed above, we consider English medium education as a proxy variable for a good quality of human capital formation and Nepali medium education as a proxy variable for a poor quality of human capital formation in this paper.

In order to account for the geographical variation that may affect the education and quality of education outcomes we collected various district level information. We collect the total population and the number of schools in each district in 2011 as a proxy to account for the geographical variation in our outcome variables of interest. In order to control for household characteristics that may affect education decision, we collect various information such as number of members in a household, household living in Kathmandu valley, education of the migrant or would be a migrant worker. ${ }^{21}$ Furthermore, Nepal is popularly considered to be a migration producing country as remittance contributes more than $25 \%$ of Nepal's GDP. There is a higher chance that multiple members of a household migrate. Therefore, we also include other household members who are abroad as a proxy measure of household economic

\footnotetext{
${ }^{21}$ More than $95 \%$ of the migrants are men. Therefore, we do not consider the gender of the migrant in our regression estimation. Furthermore, the age of the migrant is positively correlated with the year of migration experience due to the EPS policy eligibility criteria. Therefore, we do not include the age of the migrant workers in our regression estimation. The number of household members includes the migrant or would be migrant. Kathmandu valley constitutes Kathmandu, Lalitpur and Bhaktapur districts.
} 
status. $^{22}$

It is essential for us to check whether our control and treatment groups are uniformly distributed. We test the randomization of the treatment and control groups in column 7 and 8 . As it can clearly observe, the control and treatment groups are uniformly distributed except one characteristic. Return migrant households are more likely to live in the Kathmandu Valley. This could be more likely due to the information gap in earlier years as pointed out in the previous literature (Gibson et al. 2011). The EPS program started in Nepal for the first time in 2008 and households from Kathmandu Valley might have had a higher chance of obtaining information earlier as compared with other parts of Nepal. Another interpretation could be that; migrant households could have moved to Kathmandu Valley after a period, as their household income got much higher in comparison with non-migrant household's income.

As we can observe from Table 1, there is no statistically significant difference in migration characteristics of a household and the rate of educational attendance of the household members in the country of origin. Similarly, we find no statistically significant impact of shortterm migration on quality of education. However, we find a positive impact of long-term migration on quality of education. We find that long-term migration is negatively associated with Nepali medium education attendance and positively associated with English medium education attendance. We conduct the regression analysis considering the control variables and present the results in the next section.

\section{Estimation Results}

In this section, we begin to analyze the impact of short and long-term migration on overall human capital formation of the household members in the country of origin. Then we estimate its impact on quality of human capital formation. We use a simple Probit model to estimate the coefficients. ${ }^{23}$ In particular, we estimate the following equation.

$$
\operatorname{Prob}(Y>0 \mid X)=1[X \gamma+\varepsilon>0]=\Phi(X \gamma)
$$

In the above model, $Y$ is the outcome variable of interest. $X$ is the vector of independent observable characteristics and $\gamma$ is the vector of coefficients. $\varepsilon$ is a random, idiosyncratic error

\footnotetext{
${ }^{22}$ Household members abroad variable does not include the respondent who is now working in South Korea. The migration experience in South Korea may be correlated with another members' migration. To check the robustness of our finding, we estimate the coefficients considering both with and without other members' migration experience. The results do not change and robust to our main findings.

${ }^{23}$ Estimating the coefficients in order probit model is also another possibility. However, in our case, it is difficult as many households responded that, their household members are attending both English as well as Nepalese medium educations.
} 
term. We clustered our standard errors at the district level while estimating the coefficients to control for unobserved variations at the district level.

\section{$\underline{\text { A. Overall Human Capital }}$}

We present the results on the impact of short and long-term migration on the overall human capital formation of household members in the country of origin in Table 2. In column 1 , we estimate the coefficients without any controls. In column 2, we estimate the coefficients by controlling for geographical characteristics that may affect the households' educational attainment. And finally, in column 3, we estimate the coefficients additionally controlling for other household characteristics.

From our analysis in column 1 of Table 2, we do not find any statistically significant relationship between the migration status of a household and their overall educational attendance of left behind. The coefficient estimated is not statistically significant. After controlling for geographical characteristics in column 2, the result remains same. And finally, the results remain unchanged as we control for other household characteristics in column 3 . Our overall finding suggests that migration status of a household have no statistically significant impact on educational attendance. The results are similar to our randomization analysis presented in the descriptive statistics in Table 1.

\section{B. Quality of Human Capital}

We present the results in Table 3. From column 1-3, we estimate the short-term and long-term impact of migration on Nepali medium educational attendance. Furthermore, from column 4-6, we estimate the short-term and long-term impact of migration on English medium educational attendance. In column 1 and 4, we estimate the coefficients without any controls. Additionally, in column 2 and 5, we estimate the coefficients by controlling for geographical characteristics that may affect the household's educational attainment. And finally, in column 3 and 6 we estimate the coefficients additionally controlling for other household characteristics.

From column 1 of Table 3, we do not find any statistically significant relationship between the short-term migration status of a household and their Nepali medium educational attendance of left behind. After controlling for households' geographical characteristics in column 2, the result remains same. And finally, the results remain unchanged as we control for other household characteristics in column 3. Similarly, from column 4 of Table 3, we do not find any statistically significant relationship between the short-term migration status of a household and their English medium educational attendance of the left behind. After 
controlling for households' geographical characteristics in column 5, the result remains same. And finally, the results remain unchanged as we control for other household characteristics in column 6. Findings from Table 3 suggest that short-term migration status of a household have no impact on quality of educational attendance.

We find a negative and statistically significant relationship between long-term migration status of a household and their Nepali medium educational attendance of the left behind in column 1 of Table 3. After controlling for households' geographical characteristics and other household characteristics in column 2 and 3 respectively, the estimated coefficient is negative and statistically significant. These results suggest that long-term migration status of a household have a negative impact on Nepali medium educational attendance.

The question then arises that, whether the households are substituting the poor-quality human capital formation (Nepali medium) with better quality. In column 4 of Table 3, we find a positive and statistically significant relationship between the long-term migration status of a household and their English medium educational attendance of left behind. After controlling for households' geographical characteristics other household characteristics in columns 5 and 6 , the coefficient is still positive and statistically significant. Findings from Table 3 suggest that long-term migration status of a household have a positive and significant impact on quality of educational attendance.

As we can find from Table 3, the magnitude of the effect is quite similar in columns 13 and 4-6. We find that long-term migrant households are 16-17 percentage points more likely to shift from a lower quality of education and substituting it with a higher quality of education of the left behind household members.

\section{Robustness}

As can be seen from the summary statistics, households living in Kathmandu Valley are different between control and the treatment groups. We included the variable to control for the variation in the main analysis. However, one may argue that the timing of migration could be associated with other unobservable characteristics that might affect our outcome of interest. For example, residents living in the Kathmandu valley are first movers and most English medium schools are located in this region. To further test the robustness of our findings, we estimate the coefficients excluding the households that are living in Kathmandu valley. The results are presented in Table 4. As we can observe, the results are similar to our main findings. We clustered our standard errors at the district level while estimating the coefficients to control 
for other unobserved variations at the district level in our main analysis. The results without clustering the standard errors are presented in Table 5. The results are similar to our main findings as well.

\section{Potential Mechanism}

In our analysis, we find that short and long-term migration has no impact on the overall education of the left behind. Furthermore, short-term migration experience has no impact on the quality of education as well. However, we find a positive impact of long-term migration experience on quality of education of the left behind. Here, we will discuss the potential mechanism behind our findings.

The literature on the positive impact of migration on education states that the remittances received relax the household credit constrains and results in an increase in education of the left behind. However, the schooling in Nepal is free up to secondary level. The Interim Constitution of Nepal (2007) guarantees free education in the mother tongue (Nepali medium) up to secondary level through public schools. Therefore, the potential mechanism behind no impact of migration on overall educational attainment might be due to free education in Nepal. However, as English medium education is costly and mostly provided by private institutions, we find a positive effect of English medium education attendance among households with long-term migration experience. This result also supports the "credit constraint' hypothesis. Our results also indicate that credit constraint may persist after the migration in the short-run.

The literature on the negative impact of migration on education stresses that the parental absence from home acts as a barrier to the household head acting as a disciplinarian and figurehead and therefore lowers the human capital formation of the children. Furthermore, children's migration followed by parent's migration and increased housework due to absence of a household member also lead to a decline in educational attainment of the left-behinds. In our context, EPS program allows applicants with 18-39 years old to migrate. Furthermore, EPS program does not allow other household members to migrate together. Due to these requirements, migrants in our setting are more likely to have completed their education and less likely to be the head of the household. Therefore, we potentially do not find any decline in overall education or decline in quality of education.

\section{Conclusion}

In this paper, we analysed the short and long-term impact of international migration on overall human capital formation as well as the quality of human capital formation of the left behind migrant household members in the community of origin. We found that the time elapsed 
since the migration event took place could affect the human capital formation of the left behind households differently. Similarly, international migration could also impact overall human capital as well as the quality of human capital formation differently.

Do the findings presented here have any broader significance? One could argue that the external validity of our findings might be limited as we examined a specific program to provide a plausible causal effect. However, we argue that the findings presented here have the possibility of broader significance. The EPS program presently recruits workers from 16 different developing countries across Asia. Therefore, our findings can be generalized to other sending countries. Furthermore, as younger people are more likely to migrate, our sample resembles the potential migrant characteristics. And finally, education is a basic human right and compulsory education (primary and secondary education in particular) is free in most developing countries. Therefore, our findings can further be generalized to other developing countries where education is free.

It is also important to note some boundary conditions of our findings. We do not have further information about other variables to measure the quality of education such as public v's private school attendance, test scores, grade progression or education spending. The above information could have helped us to additionally test the robustness of our findings. Future research in this field could address these limitations. 


\section{References}

Acharya, C. P., \& Leon-Gonzalez, R. (2014). How do migration and remittances affect human capital investment? The effects of relaxing information and liquidity constraints. Journal of Development Studies, 50(3), 444-460.

Acosta, P. (2006). Labor supply, school attendance, and remittances from international migration: the case of El Salvador. The World Bank.

Ambler, K., Aycinena, D., \& Yang, D. (2015). Channeling remittances to education: a field experiment among migrants from El Salvador. American Economic Journal: Applied Economics, 7(2), 207-32.

Andrabi, T., Das, J., Khwaja, A. I., Vishwanath, T., \& Zajonc, T. (2007). Learning and Educational Achievements in Punjab Schools (LEAPS): Insights to inform the education policy debate. World Bank, Washington, DC.

Antman, F. M. (2012). Gender, educational attainment, and the impact of parental migration on children left behind. Journal of Population Economics, 25(4), 1187-1214.

Antman, F. M. (2013). 16 The impact of migration on family left behind. International handbook on the economics of migration, (p 293).

Batista, C., Lacuesta, A., \& Vicente, P. C. (2012). Testing the 'brain gain'hypothesis: Micro evidence from Cape Verde. Journal of Development Economics, 97(1), 32-45.

Booth, M. Z. (1995). Children of migrant fathers: The effects of father absence on Swazi children's preparedness for school. Comparative Education Review, 39(2), 195-210.

Clemens, M. A., \& Tiongson, E. R. (2017). Split decisions: household finance when a policy discontinuity allocates overseas work. Review of Economics and Statistics, 99(3), 531-543.

Dinkelman, T., \& Mariotti, M. (2016). The long-run effects of labor migration on human capital formation in communities of origin. American Economic Journal: Applied Economics, 8(4), 1-35.

Duflo, E., Dupas, P., \& Kremer, M. (2011). Peer effects, teacher incentives, and the impact of tracking: Evidence from a randomized evaluation in Kenya. American Economic Review, 101(5), 1739-74.

Edwards, A. C., \& Ureta, M. (2003). International migration, remittances, and schooling: evidence from El Salvador. Journal of development economics, 72(2), 429-461. 
Giannelli, G. C., \& Mangiavacchi, L. (2010). Children's schooling and parental migration: Empirical evidence on the 'left-behind'generation in Albania. Labour, 24, 76-92.

Gibson, J., McKenzie, D., \& Stillman, S. (2011). The impacts of international migration on remaining household members: omnibus results from a migration lottery program. Review of Economics and Statistics, 93(4), 1297-1318.

Gibson, J., McKenzie, D., \& Stillman, S. (2013). Accounting for selectivity and durationdependent heterogeneity when estimating the impact of emigration on incomes and poverty in sending areas. Economic Development and cultural change, 61(2), 247-280.

Hanson, G. H., \& Woodruff, C. (2003). Emigration and educational attainment in Mexico. Mimeo., University of California at San Diego.

Mckenzie, David, and Hillel Rapoport. "Can migration reduce educational attainment? Evidence from Mexico." Journal of Population Economics 24, no. 4 (2011): 1331.

Mergo, T. (2016). The effects of international migration on migrant-source households: Evidence from Ethiopian diversity-visa lottery migrants. World Development, 84, 69-81.

Ministry of Education, Government of Nepal, and United Nations Educational, Scientific and Cultural Organization Office in Kathmandu. (2015). Education for all national review report 2001-2015.

Ministry of Education, Government of Nepal, (2015). Nepal Education in Figures AT-AGLANCE

http://www.moe.gov.np/assets/uploads/files/Nepal_Education_in_Figures_2015.pdf

Ministry of Education, Government of Nepal, (2016). School Sector Development Plan 2016/17-2022/23

http://www.moe.gov.np/assets/uploads/files/SSDP_Book_English_Final_July_5,_2017.pdf Ministry of Labour and Employment, Government of Nepal, (2016). Labour Migration for Employment A Status Report for Nepal: 2014/2015

Rapoport, H., \& Docquier, F. (2006). The economics of migrants' remittances. Handbook of the economics of giving, altruism and reciprocity, 2, 1135-1198.

Sur, P. K., \& Sasaki, M. (2019). Migration and natural disaster: Ex-ante preparedness and contribution to ex-post community recovery. Migration Studies, 7(2), 220-244. 
Thapa, A. (2015). Public and private school performance in Nepal: an analysis using the SLC examination. Education Economics, 23(1), 47-62.

Yang, D. (2008). International migration, remittances and household investment: Evidence from Philippine migrants' exchange rate shocks. The Economic Journal, 118(528), 591-630. 
Figure 1: Eligibility, Implementation and Employment Procedure for the EPS program

Eligibility to apply for EPS-TOPIK

- Person aged between 18 and 39

- Person with no criminal record in relation to serious offence punishable by imprisonment

- Person with no past records of deportation or departure under a departure order from the Republic of Korea

- Person who is not subject to travel ban in his/her home country

- Person who fulfills the eligibility requirements decided by both country

$>$ Implementation of EPS-TOPIK

- Implemented at each country considering the number of valid rosters and anticipated roster-exhausting time

- Specific schedule and details are announced in advance

\section{$>$ EPS-TOPIK questions}

- Listening (25 questions) and reading comprehension (25 questions) (Total test time is 70 minutes)

- EPS-TOPIK Question book : Download Link (http://eps.hrdkorea.or.kr)

Announcement of test passers

- How to announce

- Announced through web page on designated day after EPS-TOPIK implemented

* Home page address : http://eps.hrdkorea.or.kr, http://epstopik.hrdkorea.or.kr

- Posted at Sending Agency in sending country

- Pass Criteria : Among the candidates who scored over 80 points (full marks 200), designated number of candidates will pass in order of highest score

- Valid term of EPS-TOPIK : 2 years from announcement date of test result

\section{$>$ Others}

- Even the candidates pass the EPS-TOPIK, they only obtain qualification to be registered in EPS Pool through Job application, it does not guarantee employment in Korea

* * Reference (summary of employment procedure)
1. EPS-TOPIK pass
2. Job application
3. Roster making and registration
4. Introducing foreign workers (Random)
5. Employment

Source: https://www.eps.go.kr/ph/index.html?natNm=ph 
Figure 2: EPS Process

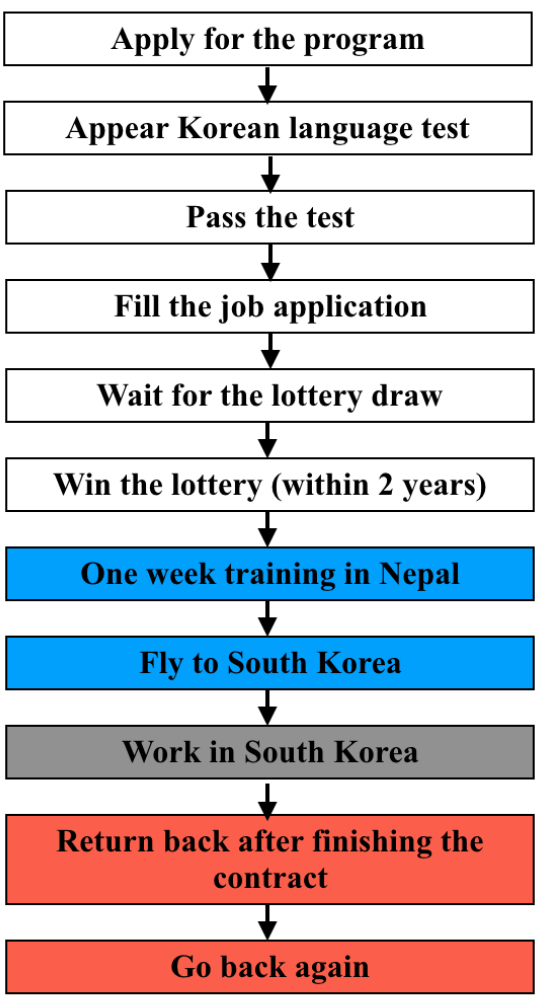


Table 1: Summary Statistics and the Test of Randomization

\begin{tabular}{|c|c|c|c|c|c|c|c|c|}
\hline & \multicolumn{2}{|c|}{$\begin{array}{l}\text { No Migration } \\
\text { Experience }\end{array}$} & \multicolumn{2}{|c|}{$\begin{array}{l}\text { Short Term } \\
\text { Migration } \\
\text { Experience }\end{array}$} & \multicolumn{2}{|c|}{$\begin{array}{l}\text { Long Term } \\
\text { Migration } \\
\text { Experience }\end{array}$} & \multicolumn{2}{|c|}{ Differences } \\
\hline & (1) & (2) & (3) & (4) & (5) & (6) & (7) & (8) \\
\hline Variables & Mean & St Dev & Mean & St Dev. & Mean & St Dev & (3) - (1) & $(5)-(1)$ \\
\hline Anyone Studying (Yes) & 0.789 & 0.409 & 0.782 & 0.416 & 0.882 & 0.325 & -0.007 & 0.093 \\
\hline Studying in Nepali Medium & 0.433 & 0.497 & 0.448 & 0.500 & 0.275 & 0.451 & 0.015 & $-0.159 * *$ \\
\hline Studying in English Medium & 0.461 & 0.500 & 0.425 & 0.497 & 0.627 & 0.488 & -0.036 & $0.166^{* *}$ \\
\hline Log population of the District & 12.768 & 0.705 & 12.836 & 0.609 & 12.860 & 0.689 & 0.068 & 0.092 \\
\hline Log No of school in the District & 6.314 & 0.323 & 6.334 & 0.293 & 6.351 & 0.336 & 0.020 & 0.037 \\
\hline No of household members & 6.349 & 2.750 & 6.698 & 3.368 & 6.471 & 3.781 & 0.349 & 0.122 \\
\hline Household member abroad & 0.445 & 0.498 & 0.376 & 0.487 & 0.420 & 0.499 & -0.069 & -0.025 \\
\hline $\begin{array}{l}\text { Household living in Kathmandu } \\
\text { Valley }\end{array}$ & 0.053 & 0.224 & 0.037 & 0.189 & 0.104 & 0.309 & -0.016 & $0.052 * *$ \\
\hline Education of the migrant member & 12.921 & 2.218 & 13.333 & 2.139 & 13.157 & 2.485 & 0.412 & 0.343 \\
\hline No of observations & & & & & & & & \\
\hline
\end{tabular}


Table 2: Overall Human Capital

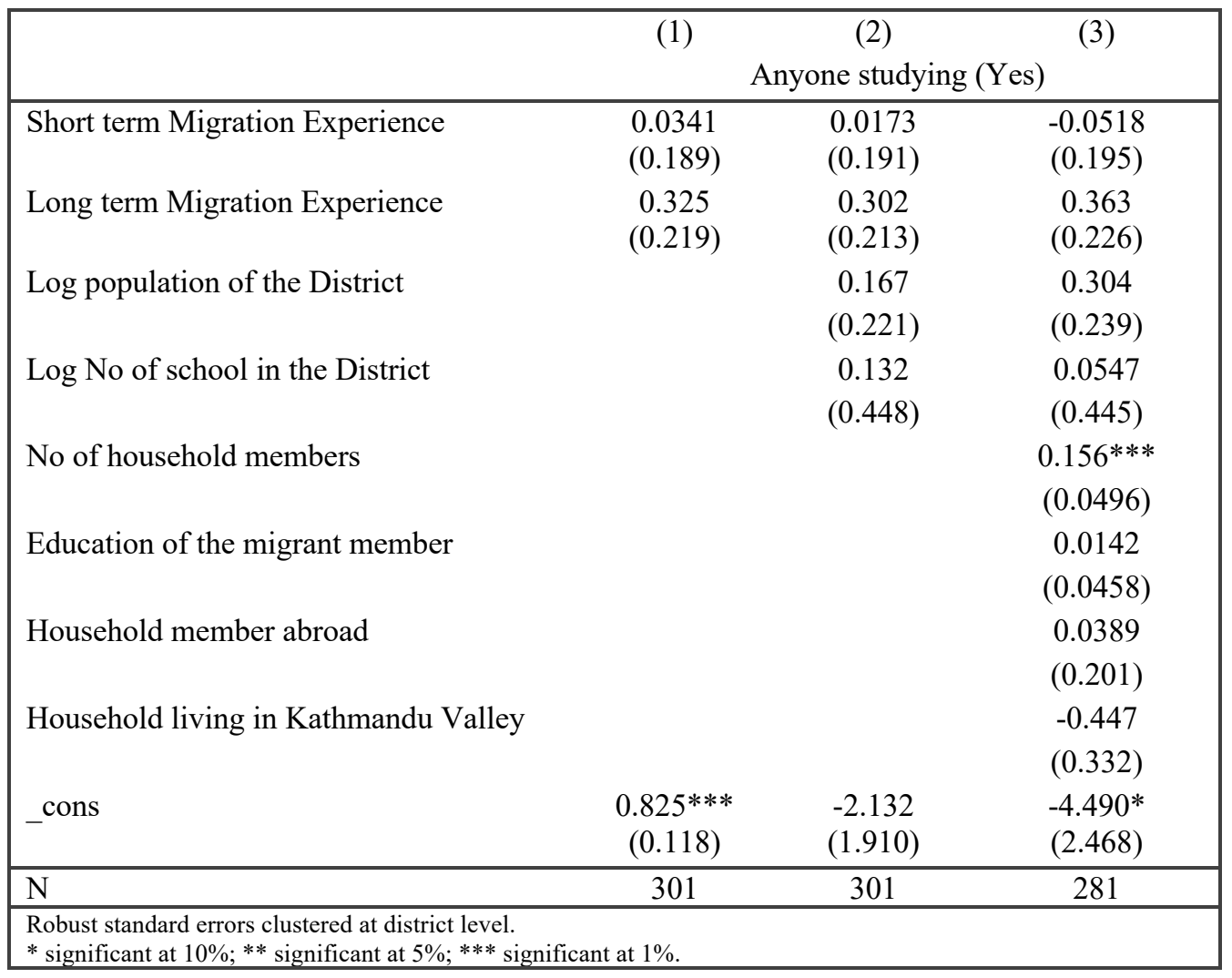


Table 3: Quality of Human Capital

\begin{tabular}{|c|c|c|c|c|c|c|}
\hline & (1) & (2) & (3) & (4) & (5) & (6) \\
\hline & \multicolumn{3}{|c|}{ Studying in Nepali Medium } & \multicolumn{3}{|c|}{ Studying in English Medium } \\
\hline Short term Migration Experience & $\begin{array}{l}0.0468 \\
(0.193)\end{array}$ & $\begin{array}{l}0.0465 \\
(0.192)\end{array}$ & $\begin{array}{l}0.0174 \\
(0.202)\end{array}$ & $\begin{array}{l}-0.0727 \\
(0.201)\end{array}$ & $\begin{array}{l}-0.0902 \\
(0.215)\end{array}$ & $\begin{array}{l}-0.116 \\
(0.215)\end{array}$ \\
\hline Long term Migration Experience & $\begin{array}{c}-0.505^{* *} \\
(0.200)\end{array}$ & $\begin{array}{c}-0.498 * * \\
(0.207)\end{array}$ & $\begin{array}{c}-0.470 * * \\
(0.207)\end{array}$ & $\begin{array}{c}0.455^{* *} \\
(0.224)\end{array}$ & $\begin{array}{l}0.426^{*} \\
(0.224)\end{array}$ & $\begin{array}{c}0.419^{* *} \\
(0.205)\end{array}$ \\
\hline Log population of the District & & $\begin{array}{l}0.198 \\
(0.205)\end{array}$ & $\begin{array}{c}0.230 \\
(0.203)\end{array}$ & & $\begin{array}{c}0.143 \\
(0.189)\end{array}$ & $\begin{array}{c}0.218 \\
(0.202)\end{array}$ \\
\hline Log No of school in the District & & $\begin{array}{l}-0.600 \\
(0.469)\end{array}$ & $\begin{array}{l}-0.413 \\
(0.499)\end{array}$ & & $\begin{array}{c}0.594 \\
(0.373)\end{array}$ & $\begin{array}{c}0.334 \\
(0.401)\end{array}$ \\
\hline No of household members & & & $\begin{array}{c}0.0356 \\
(0.0233)\end{array}$ & & & $\begin{array}{l}0.0508^{*} \\
(0.0275)\end{array}$ \\
\hline $\begin{array}{l}\text { Education of the migrant } \\
\text { member }\end{array}$ & & & $\begin{array}{c}0.0700^{* *} \\
(0.0333)\end{array}$ & & & $\begin{array}{l}-0.0495 \\
(0.0414)\end{array}$ \\
\hline Household member abroad & & & $\begin{array}{c}0.191 \\
(0.127)\end{array}$ & & & $\begin{array}{l}-0.0531 \\
(0.178)\end{array}$ \\
\hline $\begin{array}{l}\text { Household living in Kathmandu } \\
\text { Valley }\end{array}$ & & & $\begin{array}{l}-0.669^{*} \\
(0.390)\end{array}$ & & & $\begin{array}{l}0.186 \\
(0.303)\end{array}$ \\
\hline _cons & $\begin{array}{l}-0.169 * \\
(0.0943)\end{array}$ & $\begin{array}{l}1.097 \\
(1.769)\end{array}$ & $\begin{array}{l}-1.693 \\
(2.010)\end{array}$ & $\begin{array}{l}-0.0807 \\
(0.118)\end{array}$ & $\begin{array}{c}-5.664 * * * \\
(1.331)\end{array}$ & $\begin{array}{c}-4.623 * * \\
(2.023)\end{array}$ \\
\hline $\mathrm{N}$ & 301 & 301 & 281 & 301 & 301 & 281 \\
\hline
\end{tabular}


Table 4: Estimation Excluding Households Living in Kathmandu Valley

\begin{tabular}{|lccc|}
\hline & $(1)$ & $(2)$ & $(3)$ \\
& $\begin{array}{c}\text { If anyone is } \\
\text { studying (Yes) }\end{array}$ & $\begin{array}{c}\text { Studying in Nepali } \\
\text { Medium }\end{array}$ & $\begin{array}{c}\text { Studying in English } \\
\text { Medium }\end{array}$ \\
\hline Short term Migration Experience & -0.077 & 0.027 & -0.129 \\
& $(0.203)$ & $(0.206)$ & $(0.219)$ \\
Long term Migration Experience & $0.413^{*}$ & $-0.486^{* *}$ & $0.489 * *$ \\
& $(0.251)$ & $(0.207)$ & $(0.216)$ \\
No of household members & $0.152^{* * *}$ & 0.044 & 0.047 \\
& $(0.051)$ & $(0.027)$ & $(0.029)$ \\
Education of the migrant member & 0.027 & $0.0716 * *$ & -0.042 \\
& $(0.046)$ & $(0.034)$ & $(0.042)$ \\
Household member abroad & 0.094 & 0.204 & -0.032 \\
& $(0.211)$ & $(0.129)$ & $(0.184)$ \\
Log population of the District & 0.298 & 0.215 & 0.230 \\
& $(0.237)$ & $(0.205)$ & $(0.201)$ \\
Log No of school in the District & 0.187 & -0.246 & 0.252 \\
& $(0.478)$ & $(0.517)$ & $(0.416)$ \\
cons & $-5.408 * *$ & -2.633 & $-4.349 * *$ \\
& $(2.635)$ & $(2.067)$ & $(2.120)$ \\
\hline N & 265 & 265 & 265 \\
\hline Robust standard errors clustered at district level. & & \\
* significant at 10\%; $* *$ significant at $5 \% ; * *$ significant at $1 \%$ & & \\
\hline
\end{tabular}


Table 5: Robust Standard Error Estimates

\begin{tabular}{|c|c|c|c|}
\hline & $\begin{array}{c}(1) \\
\text { If anyone is } \\
\text { studying (Yes) }\end{array}$ & $\begin{array}{c}\text { (2) } \\
\text { Studying in Nepali } \\
\text { Medium }\end{array}$ & $\begin{array}{c}\text { (3) } \\
\text { Studying in English } \\
\text { Medium }\end{array}$ \\
\hline Short term Migration Experience & $\begin{array}{c}-0.052 \\
(0.202)\end{array}$ & $\begin{array}{c}0.017 \\
(0.179)\end{array}$ & $\begin{array}{c}-0.116 \\
(0.182)\end{array}$ \\
\hline Long term Migration Experience & $\begin{array}{c}0.363 \\
(0.263)\end{array}$ & $\begin{array}{c}-0.470 * * \\
(0.229)\end{array}$ & $\begin{array}{c}0.419 * * \\
(0.214)\end{array}$ \\
\hline No of household members & $\begin{array}{c}0.156^{* * *} \\
(0.052)\end{array}$ & $\begin{array}{c}0.036 \\
(0.025)\end{array}$ & $\begin{array}{c}0.0508^{*} \\
(0.028)\end{array}$ \\
\hline Education of the migrant member & $\begin{array}{c}0.014 \\
(0.041)\end{array}$ & $\begin{array}{c}0.0700 * * \\
(0.035)\end{array}$ & $\begin{array}{l}-0.050 \\
(0.035)\end{array}$ \\
\hline Household member abroad & $\begin{array}{c}0.039 \\
(0.187)\end{array}$ & $\begin{array}{c}0.191 \\
(0.158)\end{array}$ & $\begin{array}{c}-0.053 \\
(0.161)\end{array}$ \\
\hline Household living in Kathmandu Valley & $\begin{array}{l}-0.447 \\
(0.475)\end{array}$ & $\begin{array}{l}-0.669 \\
(0.470)\end{array}$ & $\begin{array}{c}0.186 \\
(0.414)\end{array}$ \\
\hline Log population of the District & $\begin{array}{c}0.304 \\
(0.218)\end{array}$ & $\begin{array}{c}0.230 \\
(0.187)\end{array}$ & $\begin{array}{c}0.218 \\
(0.188)\end{array}$ \\
\hline Log No of school in the District & $\begin{array}{c}0.055 \\
(0.466)\end{array}$ & $\begin{array}{c}-0.413 \\
(0.434)\end{array}$ & $\begin{array}{c}0.334 \\
(0.419)\end{array}$ \\
\hline cons & $\begin{array}{l}-4.490 * \\
(2.455)\end{array}$ & $\begin{array}{l}-1.693 \\
(2.044)\end{array}$ & $\begin{array}{c}-4.623 * * \\
(2.000)\end{array}$ \\
\hline $\mathrm{N}$ & 281 & 281 & 281 \\
\hline
\end{tabular}

